\title{
Parents' information needs and preferences related to bronchiolitis: a qualitative study
}

\author{
Alyson Campbell RN BScN, Lisa Hartling PhD, Samantha Louie-Poon RN BScN, \\ Shannon D. Scott PhD RN
}

Abstract

Background: Bronchiolitis affects more than one-third of children less than age 2 years and can cause substantial anxiety for parents, leading them to seek information on how to care for their sick child. The aim of our qualitative study was to explore the information needs and preferences of parents caring for a child with bronchiolitis.

Methods: We used a qualitative descriptive approach. Participants were recruited by means of purposive sampling from Oct. 1, 2017, to Mar. 15, 2018 from the Stollery Children's Hospital emergency department, a specialized pediatric emergency department in Edmonton. Individual semistructured interviews were conducted.

Results: Fifty-three parents were recruited to participate, of whom 30 could not be reached after 4 contact attempts and 8 refused. Thus, 15 parents participated (16 children). Three major themes were identified: 1) parents' information needs about bronchiolitis, 2) parents' preferred information sources and 3) parents' preferred information delivery formats. Participants indicated that they want and require credible, easy-to-understand information about bronchiolitis in a variety of formats, and especially valued information obtained directly from a health care professional or an evidence-based website.

Interpretation: This study provides important information about parents' information needs concerning bronchiolitis in children. Identifying the information that parents want and value in relation to acute pediatric illnesses is imperative to developing innovative educational approaches for parents that reflect patient-centred care.

ronchiolitis, an acute lower respiratory tract infection, affects more than one-third of children less than age 2 years and is the most common cause for hospital admission in the first year of life. ${ }^{1}$ Respiratory syncytial virus is the most common cause of bronchiolitis. The condition is characterized by inflammation and edema in the small airways, with increased mucus production. ${ }^{2}$ Although most instances of bronchiolitis are self-limiting, severe complications, such as pneumonia and empyema, may occur. These complications can severely affect a child's health and may result in hospital admission. ${ }^{3}$ In addition, parents suffer psychologically and emotionally through their child's illness and need support. ${ }^{4,5}$

Parental anxiety and uncertainty are common during a child's illness, leading them to seek care from their physician or at the emergency department. ${ }^{6}$ A wide variety of parental information is available, including written and online material. Parents are not always aware of this material, and if they are, the variability of clinical treatment for bronchiolitis can leave parents uncertain about whom or what sources of information they can trust. ${ }^{3,6,7}$ It is therefore imperative to understand the information needs of parents in relation to bronchiolitis, where they look for this information and how they prefer this information to be provided. The aim of this qualitative study was to explore parents' experiences and information needs caring for a child with bronchiolitis.

\section{Methods}

In this exploratory study, we used qualitative descriptive approaches. $^{8}$

\section{Setting}

Participants were recruited from Oct. 1, 2017, to Mar. 15, 2018 by means of purposive sampling 9 from the Stollery Children's Hospital emergency department, a specialized pediatric emergency department in Edmonton.

\section{Sample}

Parents were eligible if they presented to the emergency department seeking care for their child with bronchiolitis symptoms and were fluent in English. In the emergency department, clinical team members identified eligible participants via the emergency department information system and

Competing interests: None declared.

This article has been peer reviewed.

Correspondence to: Shannon Scott, ss14@ualberta.ca

CMAJ Open 2019. DOI:10.9778/cmajo.20190092 
notified the Stollery research recruitment team so potential participants could be approached after triage. Potential participants were provided with a study information letter outlining the purpose of the study.

\section{Data collection}

Participants completed demographic information forms after agreeing to participate. Research assistants trained in qualitative data collection (A.C., S.L.-P.) followed up with interested parents by telephone to schedule a semistructured qualitative interview ${ }^{10}$ at a mutually agreed-upon date, time and location. Written informed consent was obtained from all participants before the interview. The interview guide was originally developed by the senior author (S.D.S.), and adjustments were made by a research assistant (A.C.), based on results from our knowledge synthesis on bronchiolitis, to explore parent experiences with their child's bronchiolitis ${ }^{11}$ (Appendix 1, available at www.cmajopen.ca/content/7/4/ E640/suppl/DC1). Interview questions moved from general to specific, with later interviews becoming more focused. All interviews were digitally recorded and transcribed verbatim by a professional transcriptionist. Data collection and analysis occurred concurrently until no new information emerged from the interviews. ${ }^{12}$

\section{Data analysis}

Inductive thematic approaches guided our analysis. ${ }^{13} \mathrm{We}$ used NVivo 11 (QSR International) for data management. First, transcripts were read in detail several times by a research assistant (A.C.). Second, the research assistant conducted open coding of all transcripts and grouped codes into preliminary categories, which were then reviewed and discussed by all authors. Third, preliminary categories across cases were grouped into a beginning organizational framework according to recurring, emergent themes by A.C. and reviewed by all authors. The trustworthiness of the data was guided by 4 criteria: credibility, confirmability, dependability and transferability. ${ }^{14}$ We addressed credibility by obtaining a broad sample, which allowed for multiple and diverse perspectives and reduced the risk of bias from a particular participant demographic (i.e., all females, high-income). We addressed confirmability by maintaining a comprehensive audit trail, field notes, memos and interview tapes. Dependability was met by keeping a detailed audit trail documenting decisions made throughout the research process. Finally, we addressed transferability through thick descriptions of the parents' experiences. Analytic rigor was enhanced through discussions among the authors in which the coding framework, analytic procedures, preliminary findings and interpretations were reviewed. We analyzed demographic data using measures of central tendency.

\section{Ethics approval}

Ethics approval was obtained from the University of Alberta Health Research Ethics Board, and institutional approval was obtained from Alberta Health Services before participant recruitment.

\section{Results}

\section{Demographic characteristics}

Fifty-three parents were recruited to participate, of whom 30 could not be reached after 4 contact attempts and 8 refused. Thus, 15 parents participated (16 children). Demographic characteristics of the parents and children are presented in Table 1. The mean age of the children was 9 months (standard deviation $7.06 \mathrm{mo}$ ). All experienced bronchiolitis for the first time.

\section{Themes}

Three major themes emerged: 1) parents' information needs about childhood bronchiolitis, 2) parents' preferred sources to seek health information about their child and 3) parents' preferred formats to receive health information regarding their child. Each theme contained subthemes. Participant quotations supporting each theme are given in Table 2.

\section{Theme 1: Parents' information needs about childhood bronchiolitis}

Subtheme 1: recognizing severity: Parents had difficulty interpreting the meaning and severity of bronchiolitis symptoms. All children in our study experienced bronchiolitis for the first time, and parents commonly reported feeling unprepared and not knowing what to expect. Recognizing symptoms and symptom severity, and when to go to the emergency department were interpreted as fundamental information needs, and, without this knowledge, parents' ability to manage their child's illness and seek timely medical care was hindered. Recognizing symptoms and determining when to seek emergency care improved with experience for some, but not all, parents (i.e., experience of bronchiolitis with a different child). Firsttime experiences often resulted in exacerbation of the child's symptoms and lack of timely medical attention. Seven children had a hospital stay of 24 hours or more, including 2 children who were admitted to the pediatric intensive care unit. Eleven children required oxygen. Six parents reported that the number one thing they would have done differently to help their child was not to wait as long before seeking emergency care.

Subtheme 2: knowing about bronchiolitis: Parents identified wanting to know more about what causes bronchiolitis, what the treatments are, and whether or how bronchiolitis can be prevented. Many parents reported receiving little to no information about bronchiolitis from their health care providers from the time of diagnosis to the time of discharge. Many parents reported looking for information online but preferred to obtain this information from a health care provider.

\section{Theme 2: Parents' preferred sources to seek health information about their child}

Subtheme 1: talking to a health care professional: Parents commonly reported turning to a health care professional, typically their pediatrician, when their child became ill. Some parents reported calling their pediatrician first, to seek professional opinion, before going to the emergency department. Some parents reported that the decision to go to the emergency department was made by their pediatrician. Parents trusted 


\begin{tabular}{|c|c|}
\hline Variable & $\begin{array}{c}\text { No. }(\%) \text { of parents } \\
n=15\end{array}$ \\
\hline \multicolumn{2}{|l|}{ Gender } \\
\hline Male & $3(20)$ \\
\hline Female & $12(80)$ \\
\hline \multicolumn{2}{|l|}{ Age, yr } \\
\hline$<20$ & $1(7)$ \\
\hline 20-30 & $1(7)$ \\
\hline $31-40$ & $12(80)$ \\
\hline $41-50$ & $1(7)$ \\
\hline \multicolumn{2}{|l|}{ Marital status } \\
\hline Married/partnered & $13(87)$ \\
\hline Single & $2(13)$ \\
\hline \multicolumn{2}{|l|}{ Household income, \$ } \\
\hline$<25000$ & $1(7)$ \\
\hline $25000-49999$ & $1(7)$ \\
\hline 50 000-74 999 & $3(20)$ \\
\hline 75 000-99999 & $1(7)$ \\
\hline $100000-149999$ & $4(27)$ \\
\hline$\geq 150000$ & $3(20)$ \\
\hline Prefer not to answer & $2(13)$ \\
\hline \multicolumn{2}{|l|}{ Highest level of education } \\
\hline High school diploma & $2(13)$ \\
\hline Some postsecondary & $2(13)$ \\
\hline Postsecondary certificate/diploma & $3(20)$ \\
\hline Postsecondary degree & $4(27)$ \\
\hline Graduate degree & $3(20)$ \\
\hline Other & $1(7)$ \\
\hline \multicolumn{2}{|l|}{ No. of children at home } \\
\hline 1 & $4(27)$ \\
\hline 2 & $7(47)$ \\
\hline 3 & $3(20)$ \\
\hline 4 & $1(7)$ \\
\hline \multicolumn{2}{|l|}{ Child's age, yr $(n=16)^{*}$} \\
\hline$<1$ & $10(62)$ \\
\hline $1-2$ & $6(38)$ \\
\hline \multicolumn{2}{|l|}{ Length of hospital stay, $\mathrm{h}(n=16)$} \\
\hline $1-12$ & $4(25)$ \\
\hline $13-24$ & 3 (19) \\
\hline $25-48$ & $3(19)$ \\
\hline 49-72 & $3(19)$ \\
\hline$\geq 73$ & $3(19)$ \\
\hline
\end{tabular}

their pediatrician, and receiving information from him or her often relieved parents' anxiety. However, few parents reported actually receiving an adequate explanation of bronchiolitis. When parents were asked what information they received from health care professionals about bronchiolitis, common responses were "Not much" and "Nothing." In Alberta, Alberta Health Services Health Link provides around-theclock advice and general health information from a nurse via telephone 7 days a week. Six parents reported phoning Health Link when they were uncertain whether their child needed to be seen by a physician.

Subtheme 2: Internet: In addition to seeking information from health care professionals, 12 parents reported turning to the Internet to learn about bronchiolitis. Parents used Internet search engines (e.g., Google) to look up their child's symptoms (e.g., runny nose, fever, cough) before going to the emergency department, as many did not know to specifically search for "bronchiolitis." On discharge, parents searched "bronchiolitis" to find out additional information, such as signs and symptoms, treatments and prevention. When asked how they determined what Internet sources they could trust, participants distinguished between "clinical" (e.g., WebMD) versus "opinion" (e.g., social media, blogs) websites and felt they could trust the former more than the latter. Many participants advised against using social media to seek health information. Participants preferred Internet sources that provided information in lay terms and were Canadian-based.

\section{Theme 3: Parents' preferred formats to receive health information regarding their child}

Subtheme 1: written information: Six participants indicated that they preferred receiving information about bronchiolitis in written form, such as pamphlets or information sheets. They stated that a pamphlet with information outlining what bronchiolitis is, common symptoms and when to go to the emergency department would be useful. Participants felt that receiving these pamphlets before their child becomes sick, such as in their pediatrician's office during regular check-ups, at vaccination clinics or as part of a newborn discharge package, would be beneficial. Participants indicated that knowing about bronchiolitis before it happened would better prepare them for the experience.

Subtheme 2: online sources: Although participants indicated that there are untrustworthy information sources on the Internet, many still chose to look up information online. Participants commonly looked to medical websites that provided information in a simple way that they could scroll through and read. When asked about videos as a way to deliver information, few participants reported being inclined to watch these. Some, however, felt that videos could be useful for learning about such things as proper techniques for suctioning with a bulb syringe.

Subtheme 3: verbal communication: Many participants indicated that they preferred to receive information in person, especially if coming directly from a health care professional. Participants described how talking to friends and family often helped them through their experience with their child's 
Table 2 (part 1 of 2): Participant quotes supporting thematic analysis

\begin{tabular}{|c|c|}
\hline Theme/subtheme & Representative quote \\
\hline \multicolumn{2}{|c|}{ Theme 1: parents' information needs about childhood bronchiolitis } \\
\hline $\begin{array}{l}\text { Subtheme 1: recognizing } \\
\text { severity }\end{array}$ & $\begin{array}{l}\text { "I didn't really know that a virus could make my daughter have that much trouble breathing." [Interview } 3 \text {, } \\
\text { child age } 1 \mathrm{yr} \text { ] } \\
\text { "I always knew they were going to get sick, but I always thought it would be ... a 1- or 2-day thing." [Interview } \\
5 \text {, child age } 6.5 \text { mo] } \\
\text { "It was a little difficult to get at which point he actually has to go to [the emergency department]." [Interview } \\
10, \text { child age } 6 \text { wk] } \\
\text { "For a parent who doesn't have a medical background, it is very hard to understand that point where you } \\
\text { have to go right away to [the emergency department]." [Interview } 11 \text {, child age } 7 \text { mo] } \\
\text { "I think we ... waited longer [to go to the emergency department] because we thought maybe it was } \\
\text { something to recover from quickly." [Interview } 5 \text {, child age } 6.5 \text { mo] } \\
\text { "He's our third child, so we've got two kids before.... Normally, when the kids get sick, we give them Tylenol, } \\
\text { something like that, but when we notice they start to get difficulty breathing, then we know we've got to go to } \\
\text { the doctor." [Interview } 6 \text {, child age } 19 \text { mo] } \\
\text { "It's not ... 'Oh yeah, I've done this before'... it's ... 'Oh my god, what do I do again? ... This is happening } \\
\text { again? What did I do the first time? I don't remember." [Interview } 1 \text {, child age } 11 \text { mo] }\end{array}$ \\
\hline $\begin{array}{l}\text { Subtheme } 2 \text { : knowing } \\
\text { about bronchiolitis }\end{array}$ & $\begin{array}{l}\text { "I didn't know a whole lot about it [bronchiolitis]." [Interview } 9 \text {, child age } 2 \mathrm{yr}] \\
\text { "I was asking ... how it has been caused? And ... what is the source of these symptoms?" [Interview } 1 \text {, child } \\
\text { age } 11 \text { mo] } \\
\text { "They [health care team] didn't really explain ... how or what kind of symptoms I should be looking for." } \\
\text { [Interview } 1, \text { child age } 11 \mathrm{mo} \text { ] } \\
\text { "To be honest ... I had Googled it a bit. So I knew to look for in-drawing. ... Nobody had really told me that." } \\
\text { [Interview } 13, \text { child age } 7 \mathrm{mo} \text { ] }\end{array}$ \\
\hline \multicolumn{2}{|c|}{ Theme 2: parents' preferred sources to seek health information about their child } \\
\hline $\begin{array}{l}\text { Subtheme 1: talking to a } \\
\text { health care professional }\end{array}$ & $\begin{array}{l}\text { "I'll just call the pediatrician and just take an appointment. ... At some point, it's just saying ... 'I'm going to try to } \\
\text { rely on somebody who's more knowledgeable than me for this specific problem.” [Interview } 3 \text {, child age } 14 \text { mo] } \\
\text { "I called the doctor — we had gone already a couple of times to the doctor. But I called and I ... said that he } \\
\text { wasn't getting better, and I asked if I should bring him back in. This was about } 5 \text {... or } 6 \text { days after he originally } \\
\text { got sick. And then, when we went in to our pediatrician's office, he rushed us for a chest x-ray and some blood } \\
\text { work, and then back to his clinic, and by the time we had got back to his clinic, he had read the chest x-ray } \\
\text { report. He then contacted [Emergency Medical Services] to take us to the Stollery." [Interview } 4 \text {, child age } 16 \text { mo] } \\
\text { "As much as we wanted to go home, it was really good that he [pediatrician] had him admitted. Because ... } \\
\text { that ... really alleviated any fears that were left in me, because I knew ... he was being looked after by } \\
\text { medical professionals." [Interview } 1 \text {, child age } 11 \text { mo] } \\
\text { "I was calling Health Link ... because ... it's totally helpful to talk to somebody." [Interview } 11 \text {, child age } 7 \text { mo] } \\
\text { "Normally when they get sick, we call the Health Link line. That — it's our number one." [Interview } 6 \text {, child age } \\
19 \text { mo] }\end{array}$ \\
\hline Subtheme 2: Internet & $\begin{array}{l}\text { "Google is ... a mom's ... best friend." [Interview } 1 \text {, child age } 11 \text { mo] } \\
\text { "I Googled ... worsening coughs and ... fever lasting longer than } 3 \text { days." [Interview } 2, \text { child age } 3 \text { mo] } \\
\text { "If I see ... symptoms that seem to me, strange, other than being a normal cold, then, yes. I check online." } \\
\text { [Interview } 14 \text {, child age } 1 \mathrm{yr} \text { ] } \\
\text { "I'll look at ... the Mayo Clinic or ... [websites] that I know are actually from the health care field and not just } \\
\text { somebody's experience." [Interview } 12, \text { child age } 5 \mathrm{mo} \text { ] } \\
\text { "A clinical ... status. ... WebMD is a good site }- \text { for me, anyway." [Interview } 1 \text {, child age } 11 \text { mo] } \\
\text { "I am a part of ... the parent groups [on social media], but I don't ask for ... health information through } \\
\text { those." [Interview } 13, \text { child age } 2 \text { mo] } \\
\text { "There's some [websites] that are meant for ... parents to ... summarize ... in layman's terms, pretty much. ... } \\
\text { Symptoms to look for, and what you need to do, when you need to bring the baby to the hospital." [Interview } 1 \text {, } \\
\text { child age } 11 \text { mo] }\end{array}$ \\
\hline
\end{tabular}

illness. Receiving face-to-face confirmations and reassurances about their child's illness and treatment plan relieved anxiety.

\section{Interpretation}

Our findings build on a mixed-methods systematic review conducted by our research team on the experiences and information needs of parents related to bronchiolitis. ${ }^{11}$ The systematic review showed that parents need information about bronchiolitis, but limited research is available to inform the type, timing and source of information parents would find most useful. Findings from the current study address these limitations. Parents' information deficits were evident in their comments (e.g., What causes bronchiolitis? How can I prevent my children from getting bronchiolitis?) and the selfreported frequency of emergency department visits. All 15 parents reported taking their child to the emergency department 1-5 times. Parents felt they received insufficient 
Table 2 (part 2 of 2): Participant quotes supporting thematic analysis

\begin{tabular}{|c|c|}
\hline Theme/subtheme & Representative quote \\
\hline \multicolumn{2}{|c|}{ Theme 3: parents' preferred formats to receive health information regarding their child } \\
\hline $\begin{array}{l}\text { Subtheme 1: written } \\
\text { information }\end{array}$ & $\begin{array}{l}\text { "If there would be a pamphlet that describes the ... sickness ... not in a very scientific, but simple way ... } \\
\text { how it happens, and what are the causes and what parents can do about that, or what are the ways that we } \\
\text { can protect the children more [from] this type of virus." [Interview } 14 \text {, child age } 1 \mathrm{yr} \text { ] } \\
\text { "Pamphlets are good. Maybe if parents bring their kids in for flu shots, that can be ... given to them. Like a pamphlet } \\
\text { about bronchiolitis, because I didn't know about it until it happened to my kids." [Interview } 1 \text {, child age } 11 \text { mo] } \\
\text { "Because bronchiolitis is so hard on newborns ... [a pamphlet in] the discharge package, when you're } \\
\text { leaving ... the hospital from having the babies, might not be a bad idea." [Interview } 8 \text {, child age } 10 \text { wk] }\end{array}$ \\
\hline $\begin{array}{l}\text { Subtheme 2: online } \\
\text { sources }\end{array}$ & $\begin{array}{l}\text { "There's the ... Canadian Paediatric Society. There's ... Health Kids. I guess that knowing that these websites } \\
\text { that you can trust exist." [Interview } 3 \text {, child age } 14 \text { mo] } \\
\text { "Other people don't like reading, so watching videos, I think that works ... but sometimes people need to see } \\
\text { words written, or sometimes ... in Canada, we have language barriers. So I feel ... information in the video is } \\
\text { too fast." [Interview } 15, \text { child age } 6 \text { wk] } \\
\text { "Social media or something, it's something I would probably ignore, wouldn't notice." [Interview } 10, \text { child age } 2 \text { yr]. }\end{array}$ \\
\hline $\begin{array}{l}\text { Subtheme 3: verbal } \\
\text { communication }\end{array}$ & $\begin{array}{l}\text { "The best way [to deliver information] is person to person." [Interview } 15 \text {, child age } 6 \text { wk] } \\
\text { "For me, it's been having a good pediatrician ... someone I know that I can call." [Interview } 2 \text {, child age } 3 \mathrm{mo} \text { ] } \\
\text { "I do have a lot of nursing friends. And so I text them and ... they ... they're moms as well. So they ... have } \\
\text { pretty good input." [Interview } 1 \text {, child age } 11 \mathrm{mo} \text { ] }\end{array}$ \\
\hline
\end{tabular}

information on how to recognize symptom severity, especially those who experienced bronchiolitis with their child for the first time. Parents often overlooked symptoms of bronchiolitis such as rapid breathing and in-drawing until an emergency occurred. Our mixed-methods review showed that parents often have difficulty assessing the seriousness of respiratory tract infections. ${ }^{11}$ Similarly, in previous qualitative work, parents found they could tell their child was sick but could not always identify signs specific to bronchiolitis. ${ }^{15}$ Yael and colleagues ${ }^{16}$ reported that parents sometimes felt unaware of which symptoms might warrant further medical care. Inaccurately estimating the severity of bronchiolitis may lead to missed opportunities for timely treatment, resulting in a serious threat to a child's well-being. In the current study, 7 of 16 children were admitted to hospital, with a stay at least 24 hours; 2 of the children required intensive care.

The parents in our study suggested that receiving educational information about bronchiolitis before their child got sick would have been helpful. This is congruent with findings from Neill and colleagues ${ }^{17}$ suggesting that educational material to help assess illness severity may be effective in supporting parents to care for their children and seek help only when necessary. Our findings suggest that working with parents to promote an understanding on how to accurately interpret bronchiolitis symptoms may enhance parent confidence while reducing anxiety and unnecessary emergency department visits.

Our participants indicated that they prefer to receive information from a trusted health care professional (pediatrician, family physician, nurse) when they have a sick child. This finding is congruent with other research examining where parents prefer to look for health information for pediatric conditions such as respiratory syncytial virus, otitis media and gastroenteritis. ${ }^{18-21}$ Furthermore, for worried parents, nothing will replace face-to-face reassurance from a health care professional. ${ }^{22}$ Although parents in our study valued and preferred to receive information from a health care professional, few reported receiving adequate explanations on the nature of bronchiolitis, treatment options or illness trajectory. This finding is consistent with Peeler and colleagues' ${ }^{15}$ observation that mothers described not being informed about how their child's illness would progress and what the prognosis would be. Similarly, Cabral and colleagues ${ }^{23}$ found that parents can find it difficult to understand acute illnesses in their child and feel disempowered by inadequate information sharing by doctors. Our study and others ${ }^{15,22,23}$ suggest that missed opportunities occur to inform parents about the appropriate care and management of respiratory tract infections.

Parents in our study indicated that receiving timely information verbally, in written form or from a credible website would be helpful and preferred. This is consistent with research indicating that receipt of timely information about a child's illness can help alleviate parental fears and establish trusting relationships with health care professionals. ${ }^{15}$ This finding suggests a critical need to develop appropriate and accessible information to share with parents.

Although parents may seek information from a variety of sources to learn about their child's bronchiolitis, these may not always be reputable. ${ }^{3}$ Our participants reported turning to the Internet for symptoms and treatments of bronchiolitis, despite recognizing that Internet sources cannot always be trusted. Parental need for high-quality Internet-based resources is not surprising given that parents are increasingly using the Internet to access health information. In a 20062007 survey of 360 parents, $52 \%$ sought health information for their children on the Internet. ${ }^{24}$ Our findings further suggest that providing parents with credible information online is essential to ensuring they are making well-informed decisions about their child's health.

These findings are valuable and necessary to develop information resources about bronchiolitis that parents will find useful and relevant. Involving parents in the development of information resources about acute pediatric illnesses, like 
bronchiolitis, supports the general trend toward involving patients in research, which emphasizes the importance of working collaboratively with end-users of interventions. ${ }^{17}$ Our results will contribute to informing the development of a knowledge-translation tool for parents about bronchiolitis.

\section{Limitations}

Limitations of this study include conduct of interviews at a single point in time and only with parents who were seeking care in the emergency department. Fathers are underrepresented in this study. This is due to the reality that, in our recruitment site, mothers most often brought their child to appointments with health care professionals or for emergency department visits. Recall bias may be present, as we relied on parent self-report of their information needs. Caution should be used when generalizing the results of this study to other regions, populations and child health conditions. Participants reported high levels of income and education and were recruited in the emergency department of a tertiary care facility in an urban area in a developed country; thus, findings cannot be extrapolated to caregivers who manage bronchiolitis at home without seeking emergency care, or caregivers in other types of care centres or geographic regions.

\section{Conclusion}

Our study provides a comprehensive perspective on parents' information needs related to their child's bronchiolitis, reinforcing and adding to the existing literature on this condition. It is recognized that 1 approach to deliver information to parents about childhood bronchiolitis will not be appropriate for everyone and that a variety of techniques and resources are required. However, the results of our study reveal that, generally, parents prefer to seek health information directly from a health care professional or online, and that they value information that is easy to understand and considered credible.

\section{References}

1. Friedman JN, Rieder MJ, Walton JM; Canadian Paediatric Society, Acute Care Committee, Drug Therapy and Hazardous Substances Committee. Bronchiolitis: recommendations for diagnosis, monitoring and management of children one to 24 months of age. Paediatr Child Health 2014;19:485-91.

2. Nicolai A, Ferrara M, Schiavariello C, et al. Viral bronchiolitis in children: a common condition with few therapeutic options. Early Hum Dev 2013;89 (Suppl 3):S7-11.

3. Ingram J, Cabral C, Hay AD, et al. Parents' information needs, self-efficacy and influences on consulting for childhood respiratory tract infections: a qualitative study. BMC Fam Pract 2013;14:106-14.

4. Kamban SW, Svavarsdottir EK. Does a therapeutic conversation intervention in an acute paediatric setting make a difference for families of children with bronchiolitis caused by respiratory syncytial virus (RSV)? 7 Clin Nurs 2013;22:2723-33.

5. Leidy NK, Margolis MK, Marcin JP, et al. The impact of severe respiratory syncytial virus on the child, caregiver, and family during hospitalization and recovery. Pediatrics 2005;115:1536-46.

6. Neill SJ. Acute childhood illness at home: the parents' perspective. 7 Adv Nurs 2000;31:821-32.

7. Jackson C, Cheater FM, Reid I. A systematic review of decision support needs of parents making child health decisions. Health Expect 2008;11:232-51.

8. Sandelowski M. Focus on research methods: Whatever happened to qualitative description? Res Nurs Health 2000;23:334-40.
9. Patton MQ. Qualitative research and evaluation methods. 3rd ed. Thousand Oaks (CA): Sage Publications; 2002:209-59.

10. Patton MQ. Qualitative research and evaluation methods. 3rd ed. Thousand Oaks (CA): Sage Publications; 2002:339-429.

11. Gates M, Shulhan-Kilroy J, Featherstone R, et al. Parent experiences and information needs related to bronchiolitis: a mixed studies systematic review. Patient Educ Couns 2019;102:864-78.

12. Sandelowski M. Sample size in qualitative research. Res Nurs Health 1995;18:179-83.

13. Patton MQ. Qualitative evaluation and research methods. 3rd ed. Thousand Oaks (CA): Sage Publications; 2002:431-541.

14. Lincoln YS, Guba EG. But is it rigorous? Trustworthiness and authenticity in naturalistic evaluation. New Dir Program Eval 1986;1986:73-84.

15. Peeler A, Fulbrook P, Kildea S. The experiences of parents and nurses of hospitalised infants requiring oxygen therapy for severe bronchiolitis: a phenomenological study. 7 Child Health Care 2015;19:216-28.

16. Yael Kopacz N, Predeger E, Kelley C. Experiences of Alaskan parents with children hospitalized for respiratory syncytial virus treatment. 7 Pediatr Nurs 2013;28:e19-21.

17. Neill S, Roland D, Jones CHD, et al. Information resources to aid parental decision-making on when to seek medical care for their acutely sick child: a narrative systematic review. BM7 Open 2015;5:e008280.

18. Pignotti MS, Catarzi S, Donzelli G. A 4-year survey on palivizumab respiratory syncytial virus (RSV)-prophylaxis: How can compliance be improved? 7 Matern Fetal Neonatal Med 2006;19:221-4.

19. Xu J. What factors influence parent compliance with the respiratory syncytial virus (RSV) prevention program? [master's dissertation]. Calgary: University of Calgary; 2006.

20. Meherali S, Campbell A, Hartling L, et al. Understanding parents' experiences and information needs on pediatric acute otitis media: a qualitative study. 7 Patient Exp 2019;6:53-61.

21. Albrecht L, Hartling L, Scott SD. Pediatric acute gastroenteritis: understanding caregivers' experiences and information needs. CFEM 2017;19:198-206.

22. Jones CHD, Neill S, Lakhanpaul M, et al. Information needs of parents for acute childhood illness: determining 'what, how, where and when' of safety netting using a qualitative exploration with parents and clinicians. BMF Open 2014; 4:e003874.

23. Cabral C, Ingram J, Hay AD, et al. "They just say everything's a virus" - parents' judgment of the credibility of clinician communication in primary care consultations for respiratory tract infections in children: a qualitative study. Patient Educ Couns 2014;95:248-53.

24. Khoo K, Bolt P, Babl FE, et al. Health information seeking by parents in the Internet age. 7 Paediatr Child Health 2008;44:419-23.

Affiliations: Evidence in Child Health to Advance Outcomes (Campbell, Louie-Poon, Scott), Faculty of Nursing, University of Alberta; Alberta Research Centre for Health Evidence (Hartling), Department of Pediatrics, Faculty of Medicine and Dentistry, University of Alberta, Edmonton, Alta.

Contributors: Shannon Scott and Lisa Hartling were responsible for study conceptualization and design. Alyson Campbell and Samantha Louie-Poon obtained and analyzed the data. Alyson Campbell drafted the manuscript. All of the authors revised the manuscript critically for important intellectual content, approved the final version to be published and agreed to be accountable for all aspects of the work.

Funding: Shannon Scott's research is supported by a Canada Research Chair for Knowledge Translation in Child Health and a Distinguished Research award from the Stollery Children's Hospital Foundation. Lisa Hartling receives salary support through a Canada Research Chair for Knowledge Synthesis and Translation and is a Distinguished Researcher with the Stollery Science Lab supported by the Stollery Children's Hospital Foundation. This project was supported by research funded by the Networks of Centres of Excellence (Knowledge Mobilization Initiative), with matching dollars from the Women and Children's Health Research Institute (partnership funding).

Acknowledgements: The authors acknowledge Xuan $\mathrm{Wu}$ and Hannah Brooks for coordinating this project. They also acknowledge Mithra Sivakumar and Manasi Rajagopal for study participant recruitment.

Supplemental information: For reviewer comments and the original submission of this manuscript, please see www.cmajopen.ca/content/7/4/ E640/suppl/DC1. 